\title{
Research Paper \\ Strategy for Prevention of Bronchopulmonary Dysplasia in Newborns
}

\author{
Chu Lan Huong ${ }^{*}$, Ngo Quoc Thai, Nguyen Thi Quynh Nga \\ Vietnam National Children's Hospital, 18/879 La Thanh, Dong Da, Hanoi, Vietnam \\ Received 04 March 2020 \\ Revised 27 March 2020; Accepted 15 April 2020
}

\begin{abstract}
Bronchopulmonary dysplasia (BPD) is a chronic lung disease most commonly seen in premature infants who required mechanical ventilation and oxygen therapy for acute respiratory distress. While advances in neonatal care have resulted in improved survival rates of premature infants, limited progress has been made in reducing rates of BPD. Lack of progress may in part be attributed to the limited therapeutic options available for prevention and treatment of BPD. Several lung-protective strategies have been shown to reduce risks, including use of non-invasive support, as well as early extubation and volume ventilation when intubation is required. These approaches, along with optimal nutrition and medical therapy, decrease risk of BPD; however, impacts on long-term outcomes are poorly defined. Abnormal ventilatory responses and pulmonary hypertension can further complicate disease. These pulmonary morbidities, combined with environmental and infectious exposures, may result in significant long-term pulmonary sequalae and represent a growing burden on health systems.
\end{abstract}

Keywords: Bronchopulmonary Dysplasia

\footnotetext{
Corresponding author.

E-mail address: chulanhuong1975@gmail.com

https://doi.org/10.25073/ jprp.v4i2.194
} 


\title{
Chiến lược dự phòng loạn sản phế quản phổi ở trẻ sơ sinh
}

\author{
Chu Lan Hương", Ngô Quốc Thái, Nguyễn Thị Quỳnh Nga \\ Bệnh viện Nhi Trung uoơng, 18/879 La Thành, Đống Đa, Hà Nội, Việt Nam
}

Nhận ngày 04 tháng 3 năm 2019

Chỉnh sửa ngày 27 tháng 3 năm 2020; Chấp nhận đăng ngày 15 tháng 4 năm 2020

\section{Tóm tắt}

Loạn sản phế quản phổi (Bronchopulmonary dysplasia - BPD) là một bệnh phổi mãn tính hay gặp ở trẻ sinh non cần hỗ trợ thở máy và nhu cầu oxy caotrong quá trình điều trị suy hô hấp cấp tính. Mặc dù những tiến bộ trong chăm sóc trẻ sơ sinh đã giúp cải thiện tỷ lệ sống sót của trẻ sinh non, nhưng chưa hạn chế được tỷ lệ mắc bệnh BPD. Một số chiến lược bảo vệ phổi bao gồm sử dụng hỗ trợ không xâm lấn, cũng như rút ống nội khí quản sớm đã được chứng minh làm giảm nguy cơ mắc bệnh BPD; tuy nhiên, tiên lượng lâu dài còn hạn chế do đó vẫn là một thách thức trong quản lý và gánh nặng ngày càng tăng đối với các hệ thống y tế.

Tù khóa: Loạn sản phế quản phổi

\section{Giới thiệu *}

Loạn sản phế quản phổi (Bronchopulmonary dysplasia - BPD) lần đầu tiên được báo cáo vào năm 1967 bởi Northway và cộng sự, trong một nhóm trẻ sinh non mắc bệnh phổi mãn tính sau khi được thở máy với nồng độ oxy cao trong quá trình điều trị hội chứng suy hô hấp [1].

Năm 2001, hội nghị đồng thuận được tổ chức với sự phối hợp của Viện Sức khoẻ trẻ em và Phát triển con người quốc gia (National Institute of Child Heath and Human Development - NICHD), Hội Tim Phổi- Máu quốc gia (National Heart, Lung and Blood Institute - NHLBI) và văn phòng Các bệnh hiếm (Office of Rare Diseases) đã đề ra tiêu chuẩn và định nghĩa mới cho bệnh Loạn sản phế quản phổi dựa trên tuổi thai và nhu cầu oxy [2] (Bảng 1).

\footnotetext{
*Tác giả liên hệ.

Địa chi email: chulanhuong1975@gmail.com https://doi.org/10.25073/ jprp.v4i2.194
}

\section{Chiến lược dự phòng loạn sản phế quản phổi}

\subsection{Dự phòng truớc sinh}

Dự phòng đẻ non chính là phương pháp hữu hiệu nhất để phòng chống các biến chứng và tử vong ở trẻ đẻ non, trong đó có cả bệnh phổi mạn. Vì vậy, cần sử dụng corticosteroid trước sinh ở những bà mẹ có nguy cơ đẻ non trong khoảng thời gian từ 24 đến 34 tuần. Sử dụng corticoid có tác dụng trưởng thành phổi, qua đó làm giảm khả năng mắc cũng như mức độ nặng của bệnh màng trong. Đồng thuận mới nhất của ACOG - Hiệp hội sản phụ khoa Hoa Kỳ khuyến cáo điều trị Corticosteroid trước sinh cho trưởng thành phổi thai nhi [3],

Viêm màng ối là một trong những nguyên nhân thường gặp gây sinh non, đặc biệt ở trẻ dưới 30 tuần. Ureaplasma là nhóm vi khuẩn gây bệnh thường gặp nhất có thể gây nhiễm khuẩn thai nhi mạn tính, viêm màng ối, nhiễm khuẩn ối và viêm phổi bẩm sinh tuy nhiên thực sự còn đang tranh cãi 
[4]. Viêm màng ối là một yếu tố nguy cơ của bệnh phổi mạn, tuy chưa rõ ràng về tính độc lập của yếu tố này nhưng nếu có tình trạng viêm màng ối của sản phụ, cần tiến hành điều trị sớm.

\subsection{Tại phòng đẻ}

Trong cuộc đẻ, việc thở oxy lưu lượng cao gây ra tình trạng tăng oxy có thể ảnh hưởng cả bà mẹ lẫn thai nhi. Hiện nay, với khái niệm tăng $\mathrm{O} 2$ cho mẹ sẽ giúp tăng $\mathrm{O} 2$ cho thai nhi nên trong thực hành lâm sàng thường cho bà mẹ thở oxy trong quá trình sinh nở.Trên thực tế tăng $\mathrm{O} 2$ cho mẹ không ảnh hưởng nhiều đến $\mathrm{O} 2$ trong máu của thai nhi. Hơn thế nữa, tăng $\mathrm{O} 2$ sẽ gây ra hiện tượng oxy hóa lipid tạo ra các gốc tự do và ảnh hưởng đến hệ thống chống oxy hóa, gây hại cho sản phụ và thai nhi. Vì vậy chỉ cung cấp $\mathrm{O} 2$ cho những trường hợp sản phụ thực sự có tình trạng thiếu oxy.

Ngay sau khi sinh, trẻ có nguy cơ tổn thương phổi nếu được hồi sức bằng bóp bóng. Vì vậy, quá trình hồi sức sau đẻ cũng có thể ảnh hưởng đến tiên lượng của trẻ, đặc biệt trẻ đẻ non. Theo Guideline của Hiệp hội Hồi Sức Châu Âu 2019 [5] và Hội Hồi sức Australia:

- Trẻ đủ tháng, nếu cần phải hỗ trợ hô hấp cho trẻ với áp lực dương, hỗ trợ nồng độ $\mathrm{O} 2$ ban đầu là $21 \%$. Chỉ khi trẻ vẫn tiếp tục có nhịp tim hoặc mức độ bão hòa không cải thiện, tăng nồng độ $\mathrm{O} 2$ hỗ trợ để đạt mức bão hòa phù hợp.

- Trẻ thiếu tháng dưới 35 tuần, nồng độ $\mathrm{O} 2$ hỗ trợ từ $21 \%-35 \%$.

- Trẻ < 28 tuần tuổi thai sử dụng $\mathrm{FiO} 2$ : $30 \%$, trẻ từ $28-31$ tuần $\mathrm{FiO} 2$ từ $21 \%$ $30 \%$. Trẻ $\geq 32$ tuần $\mathrm{FiO} 2: 21 \%$

Bảng 1. Tiêu chuẩn chẩn đoán bệnh loạn sản phế quản phổi theo NICHD

\begin{tabular}{|c|c|c|}
\hline Tuổi thai & $<32$ tuần & $\geq 32$ tuần \\
\hline \multirow[t]{2}{*}{ Thời điểm đánh giá* } & $\begin{array}{l}36 \text { tuần tuổi hiệu } \\
\text { chỉnh hoặc khi trẻ } \\
\text { xuất viện }\end{array}$ & $\begin{array}{l}>28 \text { ngày nhưng }<56 \text { ngày } \\
\text { sau sinh hoặc khi trẻ xuâtt } \\
\text { viện }\end{array}$ \\
\hline & \multicolumn{2}{|c|}{ Được hỗ trợ oxy > 21\% ít nhất 28 ngày kèm theo } \\
\hline $\begin{array}{l}\text { Loạn sản phế quản } \\
\text { phổi nhẹ }\end{array}$ & Tự thở khí trời & Tự thở khí trời \\
\hline $\begin{array}{l}\text { Loạn sản phế quản } \\
\text { phổi trung bình }\end{array}$ & $\begin{array}{l}\text { Cần** hỗ trợ oxy < } \\
30 \%\end{array}$ & Cần* hỗ trợ oxy < 30\% \\
\hline $\begin{array}{l}\text { Loạn sản phế quản } \\
\text { phổi nặng }\end{array}$ & $\begin{array}{l}\text { Cần * hỗ trợ oxy } \geq \\
\text { 30\% và/hoắc áp lực } \\
\text { dương PPV hoặc } \\
\text { NCPAP) }\end{array}$ & $\begin{array}{l}\text { Cần * hỗ trợ oxy } \geq 30 \% \\
\text { và/hoặc áp lực dương (PPV } \\
\text { hoặc NCPAP) }\end{array}$ \\
\hline
\end{tabular}

* Tuỳ thuộc thời điểm nào đến trước, ** Phương pháp đánh giá nhu cầu oxy của trẻ vẫn còn bỏ ngỏ.

Biểu hiện lâm sàng BPD là hậu quả cuối cùng của một quá trình đa yếu tố nguy cơ phức tạp trong đó các yếu tố trước và sau sinh ảnh hưởng đến sự phát triển bình thường của phổi chưa trưởng thành.

Tiến triển loạn sản phế quản phổi. Nguồn: Radiographic Features of Pulmonary Oxygen Toxicity in the Newborn: Bronchopulmonary Dysplasia. 


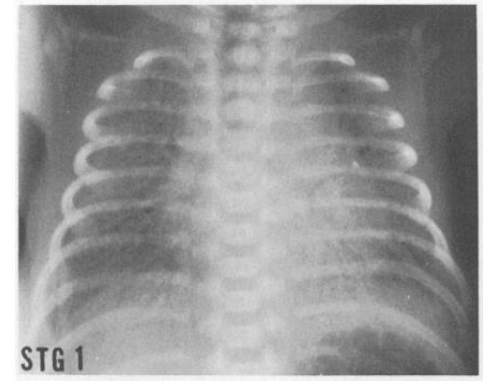

Giai đoạn I (2 - 3 ngày) - suy hô hấp cấp.

Hình ảnh trên phim Xquang "điển hình", tổn thương lan toả dạng hạt và tăng tỷ trọng nhu mô phổi kèm với tình trạng xẹp các phế nang ở mức độ hiển vi.

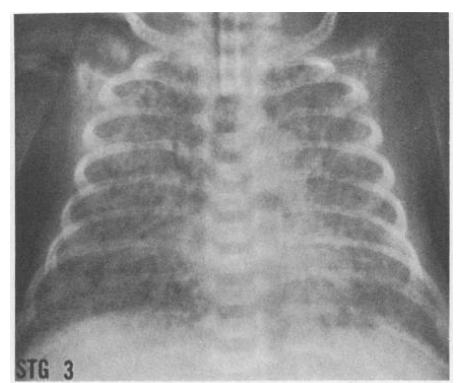

Giai đoạn III (10-20 ngày) - chuyển tiếp bệnh mạn

Hình ảnh trên phim từ mờ hoàn toàn ở giai đoạn II sang hình ảnh các nốt tròn đều không cản quang ở khắp hai trường phổi. Xen kẽ chúng là các tổ chức có mật độ cản quang bất thường.

Bão hòa oxy chấp nhận được theo bảng sau:

\begin{tabular}{|l|l|l|l|l|}
\hline 1 phút & $\begin{array}{l}60 \%- \\
65 \%\end{array}$ & & 4 phút & $\begin{array}{l}75 \%- \\
80 \%\end{array}$ \\
\hline \multirow{2}{*}{2 phút } & $\begin{array}{l}65 \%- \\
70 \%\end{array}$ & & 5 phút & $\begin{array}{l}80 \%- \\
85 \%\end{array}$ \\
\hline \multirow{2}{*}{3 phút } & $\begin{array}{l}70 \%- \\
75 \%\end{array}$ & & $\begin{array}{l}10 \\
\text { phút }\end{array}$ & $\begin{array}{l}85 \%- \\
90 \%\end{array}$ \\
\hline
\end{tabular}

Những trẻ non tháng mắc bệnh màng trong mà có nhịp tự thở, hỗ trợ hô hấp ban

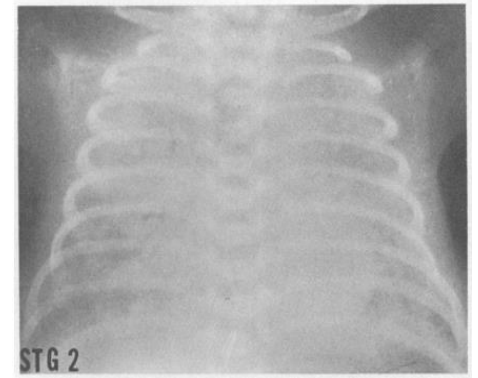
Giai đoạn II (4-10 ngày) - giai đoạn phục hồi

Phim x- quang ngực hình ảnh mờ toàn bộ trường phổi hai bên. Bờ tim bị xóa mờ hoàn toàn bởi nhu mô phổi.

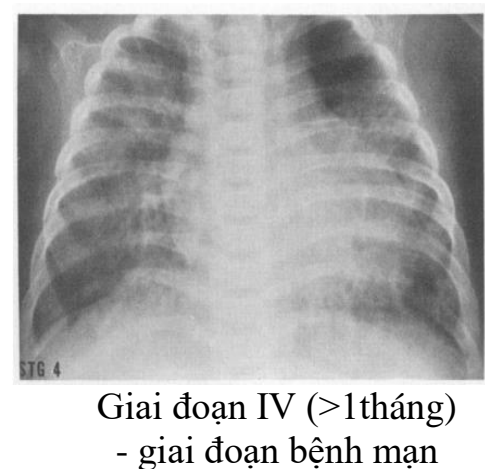

Trên x-quang thấy các bóng khí ở giai đoạn trên giãn to ra kèm theo đó là các dải tổn thương.

đầu bằng CPAP ở những trẻ $<30$ tuần khi chưa có chỉ định dặt nội khí quản bắt đầu với áp lực PEEP 6 - 8 cmH2O [6]. Nghiên cứu cho thấy với những trẻ dưới 30 tuần thai, hỗ trợ ban đầu bằng CPAP thay vì đặt ống nội khí quản có lợi ích hơn trong việc giảm thời gian cần phải đặt ống và thở máy, không có nhược điểm ngắn hạn trước mắt khi dùng CPAP. 


\subsection{Tại khoa So $\sinh$, Hồi súc so sinh}

\section{Surfactant}

Northway và cs [2] lần đầu miêu tả bệnh loạn sản phế quản phổi ở những trẻ mắc bệnh màng trong có tình trạng suy hô hấp nặng phải thở máy. Có thể thấy chính bệnh màng trong là một yếu tố nguy cơ của LSPQP, bởi nó khiến trẻ sơ sinh mắc bệnh phải thở oxy và nếu nặng phải hỗ trợ thở máy gây tổn thương phổi với các cơ chế: ngộ độc oxy, chấn thương thể tích, chấn thương xẹp cũng như là những hệ lụy viêm phổi do bội nhiễm. Vì vậy với surfactant phương pháp điều trị trong bệnh màng trong từ độ II, nó có ý nghĩa trong điều trị dự phòng bệnh phổi mạn ở trẻ sơ sinh [7]. Theo European Consensus Guideline 2019 [6] về việc quản lý RDS như sau:

- RDS khi có chỉ định surfactant, nên dùng sản phẩm chiết xuất từ thiên nhiên.

- Chiến lược surfactant điều trị được chuẩn hoá thực hành.

- RDS khi có chỉ định dùng surfactant nên được dùng sớm trước 2 giờ tuổi khi nhu cầu $\mathrm{FiO} 2>30 \%$ đã được hỗ trợ $\mathrm{CPAP}$ với áp lực PEEP tối thiểu $6 \mathrm{cmH} 2 \mathrm{O}$.

- Poractant alfa liều đầu $200 \mathrm{mg} / \mathrm{kg}$ tốt hơn $100 \mathrm{mg} / \mathrm{kg}$.

- LISA nên được áp dụng khi chỉ định surfactant cho trẻ chỉ cần hồ trợ CPAP.

- Liều thứ 2 và đôi khi liều thứ 3 được chỉ định nếu có bằng chứng RDS tiến triển.

Tuy nhiên với việc dùng surfactant tự nhiên hay tổng hợp trong điều trị bệnh màng trong ở trẻ sơ sinh, người ta thấy không có sự khác biệt về tỷ lệ mắc về việc dùng hay không dùng nhưng có sự giảm rõ tỷ lệ tử vong của trẻ được điều trị surfactant mắc bệnh phổi mạn.Tương tự với việc dùng surfactant để điều trị dự phòng cũng không có sự khác biệt trong tỷ lệ mắc bệnh nhưng tỷ lệ tử vong cũng giảm rõ.

\section{Hỗ trợ hô hấp và thở máy}

* Đích bão hòa oxy

Về mặt sinh lý, ở trẻ em và người lớn, $\mathrm{PaO} 2$ thông thường là khoảng $100 \mathrm{mmHg}$, tuy nhiên ở trẻ sơ sinh, con số này thấp hơn, chỉ vào khoảng 45-75 mmHg do tình trạng shunt trong và ngoài phổi.

Việc đặt đích $\mathrm{SpO} 2$ cao ở trẻ đẻ non không có lợi hơn gì nhiều mà còn làm tăng nguy cơ mắc bệnh võng mạc ở trẻ sinh non (Retinopathy of prematurity), làm mất cân bằng oxy, tạo ra các gốc tự do, tăng nguy cơ phụ thuộc $\mathrm{O} 2$, hình thành bệnh phổi mạn. Ngược lại nếu $\mathrm{SpO} 2$ quá thấp, lại tăng nguy cơ tổn thương cơ quan do không đủ O2 như viêm ruột hoại tử và tăng nguy cơ bại não. Đích SpO2 với trẻ đẻ non đạt 90\% - 94\%.

Nghiên cứu STOP-ROP [8] đánh giá ảnh hưởng của nồng độ oxy lên tiến triển tới bệnh võng mạc ở trẻ đẻ non, bệnh nhân được chia làm hai nhóm với đích điều trị SpO2 là $89 \%$ - 94\% và $96 \%$ - 99\%, kết quả cho thấy không có nhiều sự khác biệt giữa hai nhóm nhưng có thấy ở nhóm có độ bão hòa oxy cao hơn có thời gian cần hỗ trợ oxy dài hơn. Tương tự như vậy, trong nghiên cứu BOOST (Benefits of Oxygen Saturation Targeting) so sánh giữa hai nhóm đích bão hòa 91\%-94\% và 95\%-98\% cũng không cho thấy sự khác biệt giữa hai nhóm nhưng ở nhóm có đích bão hòa oxy cao hơn cũng có thời gian kéo dài hơn. Đồng thởi, cả hai nghiên cứu này cũng cho kết quả nhóm có đích $\mathrm{SpO} 2$ cao hơn có tỷ lệ phải sử dụng thuốc lợi tiểu và corticosteroid (trong điều trị bệnh phổi mạn) cao hơn.

* Chiến lược bảo vệ phổi ở bệnh nhân thở máy

Kiểm soát thể tích (Volume-Targeted Ventilation)

Giảm tổn thương phổi do cơ chế chấn thương thể tích bằng cách hạn chế thể tích 
khí cung cấp ở mỗi nhịp thở bằng cách cài đặt chế độ kiểm soát thể tích (VTV) cho bệnh nhân thở máy.

Áp lực, tần số và thời gian thì hít vào $(\mathrm{Ti})$

Với thông khí phút hằng định, chọn tần số cao với thể tích khí lưu thông thấp $(\mathrm{Vt})$ có hiệu quả hơn so với tần số thấp nhưng Vt lại lớn do làm giảm thiểu chấn thương thể tích.

Nghiên cứu cho thấy sử dụng Ti ngắn mặc dù không có sự khác biệt trong tỷ lệ mắc LSPQP so với Ti kéo dài nhưng lại giảm rõ tỷ lệ chấn thương phổi cấp (air leak) [9]. Với trẻ sơ sinh, có tổn thương phổi cụ thể là bệnh màng trong, nhịp thở bình thường cũng cao (> 60 nhịp/phút) nên cài đặt Ti ngắn là hoàn toàn có thể.

Để hạn chế chấn thương do áp lực, ta nên để áp lực đỉnh (PIP) thấp. Nhưng để đảm được trao đổi oxy máu và phế nang với Vt thấp và Ti ngắn, ta phải duy trì được áp lực đường thở trung bình (MAP) đủ cao. Vì vậy cần nâng áp lực dương cuối thì thở ra (PEEP) để tránh phải nâng PIP.

$$
\mathrm{P}_{\mathrm{aw}}=\frac{(\mathrm{PIP}-\mathrm{PEEP}) \times \mathrm{T}_{\mathrm{i}}}{\mathrm{T}_{\text {tot }}}+\mathrm{PEEP}
$$

Thơ máy cao tần (High Frequency

\section{Ventilation)}

Sử dụng thở máy cao tầncung cấp thể tích khí lưu thông thấp nhưng với tần số cao đủ để đảm bảo trao đồi oxy máu - phế nang, thêm vào đó khiến cho phế nang không bị giãn nở liên tục, giảm thiểu tổn thương phổi do thở máy. Tuy nhiên nghiên cứu phân tích tổng hợp năm 2010 so sánh thở HFO so với thở máy thông thường cho thấy không có sự khác biệt giữa hai hình thức về tỷ lệ mắc LSPQP cũng như các biến chứng khác

Tăng CO2 máu chấp nhận (Permissive hypercapnia)
Cơ sở của giả thuyết chấp nhận tăng $\mathrm{CO} 2$ máu là từ các nghiên cứu của Kraybill và Garland cho thấy giá trị $\mathrm{PaCO} 2$ máu cao trong những ngày đầu ở trẻ đẻ non làm giảm tỷ lệ mắc bệnh phổi mạn. Tuy nhiên nghiên cứu phân tích tổng hợp Cochranecho thấy không có bằng chứng việc chấp nhận $\mathrm{PaCO} 2$ cao làm giảm tỷ lệ mắc LSPQP. Gần đây nghiên cứu đa trung tâm PHELBI [10] với đích $\mathrm{PaCO} 2$ trong những ngày đầu trong khoảng 55-75 $\mathrm{mmHg}$ so với 40-60 $\mathrm{mmHg}$ cho thấy không có sự khác biệt về tỷ lệ mắc bệnh phổi mạn.

\section{Corticosteroid}

Corticoid trong dự phòng bệnh có tác dụng làm giảm đáp ứng viêm, cải thiện nhanh chóng chức năng phổi, tăng cường sản xuất surfactant, giảm phù nề đường thở, ổn định tính thấm mao mạch và giảm tình trạng xơ phổi.

* Corticoid đường tĩnh mạch (Dexamethasone, hydrocortison)

\section{Sử dụng sớm}

Sử dụng corticoid đường tĩnh mạch sớm là trước 96 giờ sau sinh (4 ngày) do tình trạng viêm của phổi bắt đầu rất sớm (do bệnh màng trong hoặc do viêm phổi bẩm sinh). Dùng sớm sẽ làm giảm nồng độ cytokin tiền viêm ở trong đường thở .

Tác dụng phụ của nó bao gồm thủng ruột, tăng huyết áp, tăng phì đại cơ tim và quan trọng nhất là tăng nguy cơ bại não. Tuy nhiên nếu sử dụng sớm với liều thấp làm giảm nguy cơ mắc bệnh phổi mạn và giảm tác dụng phụ [11].

Mặc dù ý nghĩa lợi ích của việc dùng sớm corticoid là hơn hẳn so với những tác dụng phụ. Nhưng với trẻ đẻ non hay rất non bằng ảnh hưởng lên phát triển hệ thần kinh là không thể chối cãi, vì vậy cần cân nhắc.

\section{Sư dụng muộn}

Sử dụng muộn là sau 7 ngày sau sinh (muộn trung bình là 7-14 ngày, rất muộn là sau 3 tuần).Sử dụng muộn cho phép ta xác 
định rõ hơn các yếu tố nguy cơ hình thành bệnh phổi mạn của trẻ. Lúc này với những trẻ có nguy cơ cao, tác dụng điều trị của thuốc lợi ích hơn hẳn so với tác dụng phụ của nó, đặc biệt là bại não.

Tác dụng của corticoid lúc này không chỉ đơn thuần là chống viêm do bệnh màng trong (và cũng không có tác dụng chống viêm được như sử dụng sớm) mà còn giúp rút ngắn thời gian thở máy của trẻ.

\section{Khí dung corticoid}

Do những tác dụng phụ của sử dụng bằng đường tĩnh mạch, câu hỏi đặt ra là sử dụng đường tại chỗ (khí dung budesonide) có tác dụng trong điều trị và dự phòng hay không.

Một phương án cũng được đề ra là sử dụng đường khí dung kết hợp với surfactant. Yeh và cs [12] tiến hành thử nghiệm bơm surfactant kèm với budesnonide cho bệnh nhân so với nhóm chứng chỉ bơm surfactant, tối đa 5 liều cách 8 h. Kết quả cho thấy chỉ có $42 \%$ ở nhóm có dùng budesonide tử vong/mắc bệnh phổi mạn trong khi ở nhóm chứng là $66 \%$. Theo dõi sau 2 năm cho thấy không có sự khác biệt về biến chứng thần kinh giữa hai nhóm.

\section{Caffein citrat}

Với tác dụng kích thích hô hấp, giảm thời gian thở máy và tác dụng lợi tiểu và giảm viêm, sử dụng caffein có tác dụng trong điều trị dự phòng LSPQP. Nghiên cứu của Schmidt cho thấy tỷ lệ mắc bệnh phổi mạn giảm tới $36 \%$. Sử dụng sớm (1-3 ngày sau sinh) cũng có lợi ích hơn hẳn: sử dụng sớm làm giảm tỷ lệ mắc $52 \%$ so với $23 \%$ khi sử dụng muộn (sau 3 ngày). Các nghiên cứu phân tích tổng hợp khác cũng cho kết quả tương tự [13].

\section{Điều trị nhiếm khuẩn}

Ureaplasma urealyticum là vi khuẩn hay gặp nhất trong viêm màng ối, thế nhưng việc nó có phải là một yếu tố gây bệnh phổi mạn không thì vẫn còn tranh cãi. Nghiên cứu tổng hợp cho thấy điều trị dự phòng erythromycin không có ảnh hưởng đến tỷ lệ tử vong và mắc LSPQP. Một nghiên cứu rộng hơn về tác dụng của kháng sinh nhóm macrolide cho thấy có giảm tỷ lệ tử vong/bệnh phổi mạn, đặc biệt là azithromycin.

\section{Dinh duõng}

Trẻ sinh non nhỏ so với tuổi thai (SGA) hoặc bị hạn chế tăng trưởng trong tử cung (IUGR) có nguy cơ tăng BPD. Các nghiên cứu đã chứng minh nguy cơ tăng gấp đôi của $\mathrm{BPD}(28 \%$ so với $14 \%)$ và tử vong sơ sinh (23\% so với $11 \%)$ với SGA, nguy cơ bị hạn chế tăng trưởng sau sinh là những thách thức trong việc cung cấp dinh dưỡng tối ưu mặc dù đã có những tiến bộ đáng kể hỗ trợ dinh dưỡng qua đường ruột. Thất bại tăng trưởng sau sinh ảnh hưởng đến tiến triển bệnh $\mathrm{BPD}$, cung cấp đủ dinh dưỡng trong tuần đầu tiên đóng một vai trò quan trọng [14].

Vitamin $A$ đóng vai trò quan trọng trong việc phát triển và biệt hóa của phổi. Vitamin $E$ có vai trò chống oxy hóa, làm giảm tình trạng mất cân bằng oxy trong cơ chế hình thành bệnh phổi mạn. Tuy nhiên tiến hành thử nghiệm so với nhóm giả dược cho thấy hai chất này không có ảnh hưởng đến tỷ lệ tử vong/bệnh phổi mạn [15].

Sữa mẹ có vai trò làm giảm tỷ lệ viêm ruột hoại tử và bệnh võng mạc ở trẻ đẻ non, tuy nhiên hiện chưa có nghiên cứu nào về vai trò của nó với bệnh LSPQP. Nghiên cứu của Spiegler [16] cho thấy nếu chỉ sử dụng đơn thuần sữa công thức thì làm tăng nguy cơ mắc bệnh phổi mạn, vì vậy với trẻ đẻ non, vẫn khuyên dùng sữa mẹ để phòng bệnh.

\section{iNO}

Nitơ oxit là một chất giãn mạch, khí dung NO có tác dụng làm giãn mạch phổi, tăng cường máu lên phổi từ đó cải thiện khả năng trao đổi khí. Ở trẻ đẻ non có bệnh lý 
phải cần sử dụng $\mathrm{NO}$, nó làm giãn mạch phổi làm giảm áp lực động mạch phổi cải thiện tưới máu từ đó giảm thời gian thở máu và nguy cơ ngộ độc oxy. Nghiên cứu EUNO cho thấy sử dụng iNO ở trẻ bệnh màng trong mức độ vừa và nặng không cải thiện tỷ lệ sống không mắc bệnh phổi mạn ở trẻ sơ sinh.

\section{Pentoxifylline}

Pentoxifylline là chất methylxanthine tổng hợp và kháng phosophodiesterase, nó có chức năng điều hòa miễn dịch - giảm sản xuất các cytokin viêm như IL6, TNF- $\alpha$ và interferon $\gamma$, các chất này đã được nhắc đến ở trên trong hình thành của bệnh phổi mạn. Đã có nghiên cứu về tác dụng bảo vệ nhu mô phổi của pentoxifylline ở thỏ và chuột.

Ở người, hiện mới chỉ có hai nghiên cứu đối chứng ngẫu nhiên của Lauterbach và Schulzke về tác dụng của khí dung pentoxifylline trong dự phòng bệnh phổi mạn. Kết quả cho thây thuốc có tác dụng giảm tỷ lệ mắc LSPQP ở trẻ đẻ non và khá an toàn, tuy nhiên cần tiến hành thêm các nghiên cứu để rõ hơn về liều, hiệu quả cũng như tính an toàn của thuốc trong điêu trị dự phòng bệnh phổi mạn ở trẻ đẻ non.

\section{$\alpha-1$-antitrypsin}

$\alpha$-1-antitrypsin có tác dụng bảo vệ phổi bằng cách tạo phức hợp với elastase tiết ra từ bạch cầu trung tính. Trong nghiên cứu thử nghiệm của Stiskal, so với nhóm giả dược thuốc có làm giảm tỷ lệ LSPQP nhưng lại chưa đủ để đạt ý nghĩa thống kê. Hiện vẫn chưa có nhiều nghiên cứu để có thể chứng minh rõ tác dụng của chúng trong dự phòng bệnh phổi mạn.

\section{Kết luận}

Loạn sản phế quản phổi là một bệnh lý thường gặp ở trẻ sơ sinh, đặc biệt là ở trẻ đẻ non, sau một thời gian dài điều trị hỗ trợ
oxy.Năm 2001, bệnh có định nghĩa và tiêu chuẩn chẩn đoán mới, không nhấn mạnh vào tổn thương xơ hóa mà tập trung vào điều kiện hình thành bệnh, mở rộng các nguyên nhân yếu tố bệnh sinh của bệnh sang hướng ngăn chặn hình thành và phát triển của phế nang.

Bệnh được hình thành bởi nhiều nguyên nhân và yếu tố nguy cơ: yếu tố nguy cơ trước sinh, trong sinh và sau sinh. Cụ thể, ảnh hưởng rõ ràng nhất là tuổi thai (hệ hô hấp chưa phát triển, tăng nguy cơ mắc bệnh màng trong gây tổn thương phổi cũng như phụ thuộc vào oxy), độc tố của oxy và tổn thương do thở máy. Ngoài ra còn có các yếu tố khác như nhiễm khuẩn, dinh dưỡng, PDA... tuy nhiên vai trò của chúng chưa thực sự rõ ràng. Nhìn chung cơ chế tổn thương của các yếu tố nguy cơ này là sự mất cân bằng oxy và yếu tố chống oxi hóa, mất cân bằng yếu tố phát triển và tình trạng viêm.

Hiện nay vẫn chưa có một khuyến cáo chính thức nào về điều trị dự phòng bệnh loạn sản phế quản phổi ở trẻ sơ sinh. Cục Quản lý Thực phẩm và Dược phẩm Mỹ FDA cũng chưa chứng nhận bất kì loại thuốc nào có tác dụng để điều trị bệnh. Đa phần các thuốc trong điều trị bệnh còn đang tranh cãi, bằng chứng chưa rõ ràng. Cần tối ưu các chiến lược bảo vể phổi trong thở máy và đích oxy trong điều trị tại khoa hồi sức sơ sinh để giảm thiểu nguy cơ mắc bệnh phổi mạn ở trẻ sơ sinh. Cụ thể, nên cài đặt máy thở kiểm soát thể tích với $\mathrm{V}_{\mathrm{t}}$ thấp và hạn chế tăng $\mathrm{PIP}$, đích $\mathrm{SpO}_{2}$ cần đạt vào khoảng $90-94 \%$ và vai trò surfactant.

\section{Tài liệu tham khảo}

[1] Northway, W.H., Jr.; Rosan, R.C.; Porter, D.Y. Pulmonary disease following respirator therapy of hyaline-membrane disease. Bronchopulmonary dysplasia. New Engl. J. 
Med 1967;276:357-368.[CrossRef] [PubMed]

[2] Jobe, A.H.; Bancalari, E. Bronchopulmonary dysplasia. Am. J. Respir. Crit. Care Med 2001; 163: 1723-1729. [CrossRef] [PubMed]

[3] Yasser Y. El-Sayed, MD, Ann E.B. Borders, MD, MSc, MPH, and the Society for Maternal-Fetal Medicine's liaison member Cynthia Gyamfi-Bannerman, MD, MSc. Antenatal Corticosteroid Therapy for Fetal Maturation. The American College of Obstetricians and Gynecologists 2017;713.

[4] Lapcharoensap, W.; Kan, P.; Powers, R.J.; Shaw, G.M.; Stevenson, D.K.; Gould, J.B.; Wirtschafter, D.D.; Lee, H.C. The relationship of nosocomial infection reduction to changes in neonatal intensive care unit rates of bronchopulmonary dysplasia. J. Pediatr 2016;180:105-109. [CrossRef] [PubMed]

[5] Wyllie J., Bruinenberg J., Roehr C.C., et al. European Resuscitation Council Guidelines for Resuscitation 2015. Resuscitation 2015; 95:249-263.

[6] David G. Sweeta Virgilio Carniellib Gorm Greisenc Mikko Hallmand Eren Ozeke Arjan te Pasf Richard Plavkag Charles C. Roehrh Ola D. Saugstadi Umberto Simeonij Christian P. Speerk Maximo Ventol Gerhard H.A. Visserm Henry L. Halliday. European Consensus Guidelines on the Management of Respiratory Distress Syndrome - 2019 Update. Neonatology 2019;115:432-450

[7] Bancalari E. and del Moral $T$. Bronchopulmonary Dysplasia and Surfactant. Neonatology 2013.

[8] STOP-ROP Multicenter Study Group (2000). Supplemental Therapeutic Oxygen for Prethreshold Retinopathy of Prematurity. Pediatrics.
[9] Klingenberg C., Wheeler K.I., McCallion N., et al. Volume-targeted versus pressurelimited ventilation in neonates. Cochrane Database Syst Rev 2017; (10).

[10] Thome U.H., Genzel-Boroviczeny O., Bohnhorst B., et al. Permissive hypercapnia in extremely low birthweight infants (PHELBI): a randomised controlled multicentre trial. Lancet Respir Med 2015; 3(7): 534-543.

[11] Baud O., Maury L., Lebail F., et al. (2016). Effect of early low-dose hydrocortisone on survival without bronchopulmonary dysplasia in extremely preterm infants (PREMILOC): A double-blind, placebo-controlled, multicentre, randomised trial. Lancet.

[12] Yeh T.F., Chen C.M., Wu S.Y., et al. Intratracheal Administration of Budesonide/Surfactant to Prevent Bronchopulmonary Dysplasia. Am J Respir Crit Care Med 2016; 193(1); 86-95.

[13] Shenk E.E., Bondi D.S., Pellerite M.M., et al. Evaluation of Timing and Dosing of Caffeine Citrate in Preterm Neonates for the Prevention of Bronchopulmonary Dysplasia. J Pediatr Pharmacol Ther 2018.

[14] Poindexter, B.B.; Martin, C.R. Impact of nutrition on bronchopulmonary dysplasia. Clin. Perinat. 2015;42: 797-806. [CrossRef] [PubMed]

[15] Darlow B.A., Graham P.J., and Rojas-Reyes M.X. Vitamin A supplementation to prevent mortality and short- and long-term morbidity in very low birth weight infants. Cochrane Database of Systematic Reviews 2016.

[16] Spiegler J., Preuß M., Gebauer C., et al. Does Breastmilk Influence the Development of Bronchopulmonary Dysplasia?. J Pediatr 2016. 